\title{
Treinamento ambiental em organizações com certificação 1SO 14001: estudo de múltiplos casos e identificação de coevolução com a gestão ambiental
}

\author{
Charbel José Chiappetta Jabbour ${ }^{\mathrm{a} *}$, Adriano Alves Teixeirab, \\ Ana Beatriz Lopes de Sousa Jabbour \\ a*prof.charbel@gmail.com, UNESP, Brasil \\ baatadrianobirigui@gmail.com, UNESP, Brasil \\ cablsjabbour@gmail.com, UNESP, Brasil
}

\begin{abstract}
Resumo
O objetivo desta pesquisa é compreender as características do treinamento ambiental em algumas empresas brasileiras. Para tanto, foram realizados nove estudos de caso com empresas certificadas pela norma ISO 14001, todas líderes em seu segmento de mercado. Foram conduzidas diversas entrevistas em cada caso, coletados documentos e realizadas visitas para observação direta. Como resultado, apresentam-se as classificações dos casos nos estágios evolutivos da gestão ambiental, os temas mais frequentes do treinamento ambiental, a diferenciação dos temas de treinamento ambiental segundo o nível hierárquico organizacional, a classificação das empresas segundo o nível de aderência às atividades de treinamento ambiental recomendadas pela literatura e as boas práticas de treinamento ambiental oferecidas pelas empresas. A principal contribuição desta pesquisa é a identificação de coevolução entre o estágio de gestão ambiental das organizações e o nível do treinamento ambiental que elas possuem.
\end{abstract}

Palavras-chave

Treinamento ambiental. Gestão ambiental. Green Human Resource Management. Sustentabilidade ambiental. Brasil.

\section{Introdução}

Geralmente, a incorporação da preocupação ambiental nas organizações ocorre por meio de alterações técnicas nos projetos de produtos e serviços e nos seus processos produtivos. Entretanto, vêm ganhando força argumentos indicativos de que a preocupação com aspectos técnicos da gestão ambiental deve ser complementada pela gestão de aspectos humanos e comportamentais que dão suporte às práticas de gestão ambiental (PERRON; CÔTÉ; DUFFY, 2006).

Esse processo é chamado pela literatura especializada de Green Human Resource Management (GHRM) (RENWICK; REDMAN; MAGUIRE, 2008). 0 GRHM diz respeito ao alinhamento de diversas práticas voltadas à gestão de recursos humanos (recrutamento, seleção, treinamento, avaliação de desempenho, recompensas etc.), aos objetivos de gestão ambiental de uma empresa (RENWICK; REDMAN;
MAGUIRE, 2008; MULLER-CAMEN et al., 2010). Trata-se de um campo de estudo multidisciplinar, emergente e ainda predominantemente teórico (MARSHALL; MAYER, 1992; HALE, 1995; DAILY; HUANG, 2001; FERNÁNDEZ; JUNQUERA; ORDIZ, 2003; GOVINDARAJULU; DAILY, 2004; JABBOUR; SANTOS, 2008).

Dentre as práticas de GHRM consideradas essenciais para o sucesso da gestão ambiental nas organizações destaca-se o treinamento ambiental. 0 treinamento ambiental é tido como "[...] one of the most important tools to develop human resources and facilitate the transition to a more sustainable society [...]" (AGENDA 21, p.345, 1992). Apesar de o treinamento ambiental ser considerado relevante desde a década de 1990 (MARSHALL; MAYER, 1992), somente recentemente algumas evidências práticas começaram a surgir. 
Empiricamente, algumas pesquisas afirmam a importância do treinamento para o sucesso da gestão ambiental nas organizações: 1) Sarkis, Gonzalez-Torres e Adenso-Diaz (2010) realizaram uma pesquisa com empresas do setor automotivo da Espanha, concluindo que o treinamento é uma variável que interfere no nível de adoção de práticas de gestão ambiental pelas empresas; 2) Cole, Elliott e Strobl (2008) conduziram uma pesquisa com empresas de Gana, chegando à conclusão de que o treinamento é uma variável que influencia positivamente o desempenho ambiental das empresas; 3) Sammalisto e Brorson (2008) também constataram que o treinamento é um aspecto chave para a implementação de práticas de gestão ambiental; e 4) Daily, Bishop e Steiner (2007) afirmam que o treinamento ambiental é relevante na capacitação das equipes que gerenciam os sistemas de gestão ambiental das organizações.

Algumas lacunas, entretanto, ainda desafiam o avanço do conhecimento sobre a relação entre treinamento ambiental e gestão ambiental nas organizações: 1) trata-se de um fenômeno recente nas organizações, o que requer maior entendimento por meio de pesquisas qualitativas, baseadas em estudo de casos (UNNIKRISHNAN; HEGDE, 2007; BRÍO; JUNQUERA; ORDIZ, 2008); 2) é necessária maior compreensão do treinamento ambiental em países em desenvolvimento, a partir de pesquisas que verifiquem diversos setores industriais (SARKIS; GONZALEZ-TORRES; ADENSO-DIAZ, 2010); e 3) é necessário considerar os estágios evolutivos da gestão ambiental nas organizações quando se estuda GHRM (JABBOUR; SANTOS; NAGANO, 2010).

Assim, algumas lacunas teórico-empíricas ainda permanecem quando se estuda a temática de treinamento ambiental: 1) quais são as principais características do treinamento ambiental em empresas de diferentes setores econômicos, manufatureiro e de serviços, em países em desenvolvimento?; 2) há relação entre o nível de treinamento ambiental e o estágio evolutivo da gestão ambiental nas organizações?; e 3) quais seriam as boas práticas de treinamento ambiental encontradas?

Dessa forma, esta pesquisa pretende contribuir com o estado da arte do tema alcançando o seguinte conjunto de objetivos ainda não explorados pelas principais pesquisas na área: 1) sistematizar as principais características do treinamento ambiental em empresas brasileiras industriais e de serviços de diversos setores econômicos; 2) classificar as empresas estudadas nos estágios evolutivos da gestão ambiental; 3) identificar boas práticas de treinamento e conscientização ambiental; e 4) verificar se há relacionamento entre a evolução da gestão ambiental e o nível do treinamento ambiental dessas organizações. Metodologicamente, esta pesquisa é qualitativa, pautando-se na realização de nove estudos de caso junto a organizações com certificação $1 S 014001$. A realização de pesquisas qualitativas baseadas em estudo de caso é recomendada para a análise de fenômenos no âmbito dos temas de GHRM e de treinamento ambiental (BRÍO; JUNQUERA; ORDIZ, 2008), mas apenas Unnikrishnan e Hegde (2007) se dedicaram, profundamente, à apresentação de uma pesquisa qualitativa sobre treinamento ambiental em empresas indianas.

A estrutura deste trabalho segue a seguinte lógica: a seção 2 apresenta a fundamentação teórica, dividida entre evolução da gestão ambiental nas organizações (seção 2.1); e GHRM e treinamento ambiental (seção 2.2). A seção 3 apresenta o método de pesquisa. A seção 4 apresenta os resultados sobre gestão ambiental (seção 4.1) e sobre treinamento ambiental (seção 4.2); na seção 4.3 é desenvolvida uma análise integrada sobre esses dois temas. A seção 5 apresenta as conclusões da pesquisa.

\section{Fundamentação teórica}

\subsection{Gestão ambiental nas organizações}

Segundo Haden, Oyler e Humphreys (2009), gestão ambiental diz respeito à completa incorporação de objetivos e estratégias ambientais aos objetivos e estratégias mais amplos existentes em uma organização. Jabbour (2010) complementa esta definição indicando que a gestão ambiental deve estar baseada em uma abordagem sistêmica para a incorporação da temática ambiental em todos os níveis organizacionais.

Diversas motivações podem levar uma empresa a adotar práticas de gestão ambiental (BERRY; RONDINELLI, 1998). Segundo González-Benito e González-Benito (2006), a pressão dos stakeholders é o principal fator que leva as organizações a buscarem uma gestão ambiental mais avançada. Além disso, uma gestão ambiental mais avançada pode melhorar a performance financeira da empresa (MOLINA-AZORÍN et al., 2009), além de aumentar a competitividade manufatureira, promovendo redução de custos, melhoria da qualidade e geração de novos produtos e processos (YANG et al., 2010). Além disso, principalmente com o avanço da consciência ambiental da população, as empresas que investem em gestão ambiental poderão se valorizar por meio de iniciativas de green marketing (WOOLVERTON; DIMITRI, 2010). 
Diversas pesquisas, entretanto, indicam que as organizações não praticam a gestão ambiental em um mesmo nível (HUNT; AUSTER, 1990, AZZONE; BERTELĖ, 1994; BORRI; BOCCALETTI, 1995; AZZONE; BERTELĖ; NOCI, 1997; WINN; ANGELL, 2000; BOIRAL, 2006; GONZÁLEZ-BENITO; GONZÁLEZ-BENITO, 2006). Esses diferentes níveis em que as empresas podem incorporar as questões ambientais têm sido chamados de estágios evolutivos da gestão ambiental (JABBOUR; SANTOS; NAGANO, 2010). Nesta pesquisa, pautando-se nas propostas de Jabbour e Jabbour (2009) e de Jabbour (2010), considera-se que as empresas podem evoluir conforme três principais estágios de gestão ambiental, ressalvando que empresas também podem se encontrar em estágios intermediários aos seguintes:

- Estágio 1. Reativo: Esse é o estágio menos desenvolvido da gestão ambiental. As organizações nesse estágio tendem a apenas atender à legislação e ao avanço da regulamentação ambiental. 0 foco do sistema de gestão ambiental é evitar que problemas ambientais ocorram, a gestão ambiental tende a ter pouca autoridade na estrutura organizacional e a empresa não se envolve em atividades externas sobre o tema ambiental;

- Estágio 2. Preventivo: Nesse estágio a organização busca estratégias para otimizar o uso de recursos naturais, por meio de ecoeficiência e da aplicação de seus princípios, como os 3 Rs (reduzir, reutilizar e reciclar). A questão ambiental começa a ser discutida pelas áreas organizacionais, a área de gestão ambiental passa a adquirir maior destaque na estrutura organizacional e algumas ações externas de gestão ambiental começam a se esboçar;

- Estágio 3. Proativo: Trata-se do último estágio de gestão ambiental. Nesse estágio, a questão ambiental é elemento fundamental da estratégia empresarial e para a criação de vantagens competitivas. Verifica-se que a área de gestão ambiental é atuante e que suas ações são integradas às demais áreas da organização. A empresa começa a implantar metodologias para a redução de impactos ambientais da cadeia produtiva e internos, como, por exemplo, a avaliação do ciclo de vida, Life Cycle Assessment - LCA, e a avaliação de fornecedores com base em critérios ambientais.

Alguns instrumentos de gestão ambiental ajudam as organizações a reduzir seus impactos ambientais, dentre os quais se destacam: 1) sistemas de gestão ambiental ISO 14001, uma certificação que atesta que a empresa definiu uma política ambiental e está buscando continuamente a melhoria de seu desempenho ambiental (MASSOUD et al., 2010; INTERNATIONAL..., 2004); 2) design for environment, que diz respeito à incorporação de preocupações ambientais no projeto de novos produtos e serviços, atribuindo às questões ambientais o mesmo status de outras questões relevantes para novos produtos, serviços e processos (PIGOSSO et al., 2010); 3) avaliação do ciclo de vida (LCA), metodologia que permite o mapeamento dos impactos ambientais ao longo da cadeia produtiva, fornecendo dados para a mitigação de impactos ambientais (POTTING; CURRAN; BLOTTNITZ, 2010).

\subsection{GHRM e treinamento ambiental nas organizações}

Para que as organizações avancem rumo à pró-atividade ambiental é necessário o suporte de diversas práticas de recursos humanos e organizacionais. Inicialmente, essas práticas ficaram conhecidas como fatores de recursos humanos (DAILY; HUANG, 2001), dimensões humanas (STONE, 2000) e dimensões de recursos humanos (JABBOUR; SANTOS, 2008). Recentemente, os pesquisadores dessa área, em consenso, vêm chamando a integração entre recursos humanos e gestão ambiental de Green Human Resource Management (GHRM) e diversos esforços vêm sendo feitos para incentivar o avanço das pesquisas nesse tema (MULLER-CAMEN et al., 2010).

0 estado da arte em GHRM aponta que as diversas práticas de recursos humanos (dentre elas o treinamento ambiental) são essenciais para que a gestão ambiental nas organizações se consolide (BRIOO; FERNÁNDEZ; JUNQUERA, 2007; DAILY; BISHOP; STEINER, 2007; BRÍ; JUNQUERA; ORDIZ, 2008; JABBOUR; SANTOS; NAGANO, 2010). Essas pesquisas vêm proporcionando um avanço no estado da arte do tema analisando em conjunto as diversas práticas de GHRM. Entretanto, ainda restam diversas oportunidades de pesquisa para entender as características e contribuições do treinamento ambiental à gestão ambiental nas organizações (SARKIS; GONZALEZ-TORRES; ADENSO-DIAZ, 2010).

A importância do treinamento ambiental começou a ser discutida na década de 1990 (MARSHALL; MAYER, 1992; HALE, 1995; BEARD, 1996; HAMMER, 1999). Sammalisto e Brorson (2008) afirmam que o treinamento ambiental serve para dois propósitos: 1) ensinar aos funcionários a política ambiental da empresa; e 2) mudar o comportamento individual, para que o funcionário estabeleça uma relação mais consciente e permanente com o meio ambiente. Esses dois propósitos fazem do treinamento uma peça-chave para tornar a sustentabilidade um paradigma dos sistemas produtivos (O'BRIEN, 1999), principalmente nos setores industriais dos países em desenvolvimento (REN, 1998).

Marshall e Mayer (1992) afirmam que o treinamento ambiental oferece oportunidade para as empresas aprimorarem suas práticas de gestão 
ambiental e obterem vantagens relacionadas à imagem corporativa e à redução de custos. Esses benefícios podem, inclusive, se estender às pequenas e médias empresas (CLOQUELL-BALLESTER et al., 2008). Os benefícios oriundos do oferecimento de treinamento ambiental ocorrem porque, quando bem projetado, ele pode contribuir para o desenvolvimento de uma cultura organizacional receptiva à gestão ambiental (BEARD, 1996).

Segundo Beard (1996), na década de 1990 muito se falava sobre o treinamento ambiental, mas pouco se sabia sobre sua real contribuição à gestão ambiental das organizações. Desde então, algumas pesquisas empíricas foram realizadas, principalmente porque o oferecimento de treinamento ambiental para todos os funcionários é um requisito para a obtenção e manutenção da certificação 1S014001 nas organizações.

Daily, Bishop e Steiner (2007) realizaram um estudo com 437 funcionários e concluíram que o treinamento ambiental influencia as equipes que se formam para gerenciar o sistema de gestão ambiental. Assim, o treinamento ambiental fornece conhecimentos essenciais para que as equipes ambientais dentro de uma organização consigam lidar com a complexidade dos problemas e oportunidades ambientais emergentes.

Brío, Junquera e Ordiz (2008), com base em oito casos empresariais, concluem que o treinamento ambiental tende a apresentar algumas similaridades entre os casos analisados, em função de ser um requisito da certificação ISO 14001, que todas as empresas estudadas possuíam. Quase todos os casos forneciam treinamento in-house e externo aos seus funcionários, sendo que os treinamentos in-house eram liderados pelos responsáveis pela gestão ambiental na empresa.

Sarkis, Gonzalez-Torres e Adenso-Diaz (2010) conduziram uma pesquisa com 157 empresas de grande porte do setor automotivo da Espanha. Eles concluíram que o treinamento ambiental é uma variável mediadora do sucesso das práticas de gestão ambiental nas empresas analisadas. Os autores comprovaram estatisticamente que as práticas de gestão ambiental somente produzem efeitos se o treinamento ambiental desempenha seu papel de intermediário, isto é, se ele é oferecido. Em outras palavras, as empresas analisadas somente adotam práticas de gestão ambiental (como eco design) se oferecerem treinamento ambiental para seus funcionários. Além disso, os autores sugerem que quanto mais técnica e complexa for uma prática de gestão ambiental adotada, mais ela será dependente de treinamento ambiental.

Unnikrishnan e Hegde (2007) conduziram estudos de caso sobre as principais características do treinamento ambiental em empresas da índia. Até o momento, este parece ser o único artigo totalmente focado em treinamento ambiental a partir de abordagem qualitativa de pesquisa. Os autores concluem que metade das empresas analisadas se preocupa com a temática treinamento ambiental. Os tipos de treinamento ambiental mais comuns são: in-house e on-the-job training. Os autores ainda concluem que o treinamento ambiental requer o apoio da alta administração e que alguns fornecedores de tecnologias mais limpas foram responsáveis por oferecer treinamento ambiental às empresas analisadas.

Apenas oferecer treinamento ambiental, entretanto, não é suficiente. Isso fica claro com os resultados da pesquisa de Perron, Côté e Duffy (2006). Esses autores compararam duas empresas (companhia $1 \mathrm{e}$ companhia 2), sendo que a companhia 1 desenvolveu um programa de treinamento ambiental para seus funcionários e a companhia 2 foi considerada um grupo de controle e não ofereceu treinamento ambiental para os funcionários. Surpreendentemente, os autores concluíram após o experimento que nas duas empresas os funcionários apresentavam um nível similar de conhecimentos sobre gestão ambiental, mesmo com a Companhia 1 tendo investido grande quantidade de recursos financeiros no seu programa de treinamento ambiental. Assim, os autores concluem que não basta oferecer treinamento ambiental. 0 treinamento ambiental deve ser planejado seguindo-se melhores práticas, como o desenvolvimento de instrumentos adequados para a avaliação dos resultados do treinamento.

Segundo a norma INTERNATIONAL...(2001), destinada à melhoria do processo de treinamento nas organizações, espera-se que o treinamento ambiental ocorra de forma cíclica, em quatro fases:

- Definição de necessidades de treinamento: diz respeito principalmente ao levantamento das necessidades de treinamento, estabelecimento de uma matriz que cruze competências requeridas e competências já desenvolvidas para o mapeamento das competências que o treinamento deverá desenvolver;

- Projeto e planejamento do treinamento: envolve a tomada de decisão sobre a atribuição, papéis e responsabilidades no processo de treinamento ambiental, treinamento para funcionários terceirizados, estabelecimento do programa de treinamento e seu oferecimento a todos os funcionários da organização, independente do cargo ocupado;

- Execução do treinamento: diz respeito à decisão sobre infraestrutura do treinamento, principalmente se o oferecimento do treinamento ambiental será in-house ou não; 
- Avaliação dos resultados do treinamento: envolve o registro do treinamento ambiental oferecido e a avaliação da satisfação dos treinados.

\section{Método da pesquisa}

Esta pesquisa é classificada como qualitativa e baseada na estratégia de múltiplos estudos de caso (YIN, 1989). 0 estudo de casos é uma estratégia de pesquisa indicada para a análise de temas emergentes nas organizações (VOSS et al., 2002). Considera-se que esta pesquisa atende aos requisitos para a utilização do estudo de casos, pois:

- Parte significativa das pesquisas existentes sobre treinamento ambiental ainda é teórica (MARSHALL; MAYER, 1992; HALE, 1995; FERNÁNDEZ; JUNQUERA; ORDIZ, 2003);

Parte das evidências empíricas, com implicações para o treinamento ambiental, são de caráter quantitativo (SARKIS; GONZALEZ-TORRES; ADENSO-DIAZ, 2010; DAILY; BISHOP; STEINER, 2007);

- Até o momento, apenas uma pesquisa sobre treinamento ambiental é baseada em análise de casos (UNNIKRISHNAN; HEGDE, 2007);

- Não foi encontrada pesquisa que relacione treinamento ambiental e evolução da gestão ambiental nas organizações em empresas brasileiras;

- Pesquisas qualitativas com análise de casos são indicadas para o estudo de temas relacionados ao GHRM (BRIO; JUNQUERA; ORDIZ, 2008).

Optou-se por analisar empresas de grande porte, pois elas tendem a tratar aspectos da gestão ambiental com maior atenção (GONZÁlEZ-BENITO; GONZÁLEZ-BENITO, 2006). Além disso, decidiu-se selecionar empresas com certificação ISO 14001, isto é, obrigadas a oferecer treinamento ambiental, que se destacassem em seu segmento e fossem atuantes em diferentes setores econômicos, de manufatura e de serviços, de vez que essas diferenças podem gerar novos insights e discussões.

Nesta pesquisa foram selecionadas nove organizações para a composição do estudo de múltiplo casos. Para fins de garantia de anonimato dessas organizações, elas serão chamadas de A, B, C, D, E, F, $\mathrm{G}, \mathrm{H}$ e $\mathrm{l}$. A escolha da quantidade de casos baseou-se na recomendação de Eisenhardt (1989), que sugere até dez casos por pesquisa. Além disso, optamos por uma quantidade de empresas próxima às existentes em pesquisas similares: oito casos (BRÍO; JUNQUERA; ORDIZ, 2008); e 16 casos (UNNIKRISHNAN; HEGDE, 2007). Outra justificativa para a escolha de nove casos é que essa quantidade permite a classificação das empresas estudadas nos três estágios da gestão ambiental aqui considerados pela pesquisa. Esse tipo de classificação exige um conjunto relativamente amplo de casos.

Após a seleção dos casos, foi elaborado o instrumento de coleta de dados. Optou-se pela elaboração de um roteiro de entrevistas. 0 roteiro de entrevista foi formulado a partir das principais questões que emergem da revisão teórica dos temas de gestão ambiental e treinamento ambiental. 0 treinamento ambiental das empresas foi analisado conforme as principais recomendações da ISO 14001 e da ISO 10015. 0 Quadro 1 apresenta as informações sobre porte e setor de atuação dos casos, perfil dos entrevistados, observação in loco realizada e documentos coletados.

\section{Resultados}

Com base nos dados coletados, as seções 4.1, 4.2 e 4.3, a seguir, se dedicam respectivamente a: caracterizar os principais aspectos da gestão ambiental das empresas, a fim de classificá-las conforme o estágio ambiental; identificar as características e práticas do treinamento ambiental; analisar o relacionamento entre gestão ambiental e treinamento ambiental.

\subsection{Evolução da gestão ambiental nos casos analisados}

A empresa A pertence ao setor de serviços financeiros, e dentre o portfólio de seus produtos estão empréstimos e financiamentos a pessoas físicas e jurídicas, gerenciamento de conta corrente, de seguros (vida, veículos e residencial), de previdência privada, de títulos de capitalização, de produtos de investimentos (fundos, poupança) etc. Foi uma das primeiras instituições bancárias do Brasil a obter certificação ISO 14001.

A organização B atua no setor de serviços para a formação técnica profissional. Sua premissa é educar e desenvolver recursos humanos para o setor industrial, com o qual mantêm estreito relacionamento. Trata-se de uma das primeiras instituições de ensino técnico profissionalizante a obter a certificação ISO 14001.

A empresa C possui como seu principal produto a celulose de eucalipto branqueada comercializada no mercado interno e externo e usada na fabricação de diversos tipos de papéis como os de imprimir e escrever, papéis sanitários, cartões para embalagens e papéis especiais.

A empresa D é uma das maiores produtoras de painéis de madeira industrializada do Hemisfério Sul e uma das líderes no mercado brasileiro de chapas de fibra, MDP (painéis de partículas de média densidade), MDF (chapas de fibra de média densidade), pisos 
Quadro 1. Síntese da dinâmica da coleta de dados.

\begin{tabular}{|c|c|c|}
\hline Empresa & Ramo de atuação/porte & $\begin{array}{c}\text { Observação direta/contatos } \\
\text { realizados }\end{array}$ \\
\hline A & $\begin{array}{l}\text { - Organização do setor } \\
\text { financeiro } \\
\text { - Grande porte }\end{array}$ & $\begin{array}{l}\text { - Uma visita com duração } \\
\text { de quatro horas e vinte } \\
\text { minutos } \\
\text { - Dois contatos por } \\
\text { telefone } \\
\text { - Quatro contatos por } \\
\text { e-mail }\end{array}$ \\
\hline
\end{tabular}

Dinâmica da coleta de dados

\section{Entrevistados}

Documentos
- Certificados e prêmios recebidos

- Política ambiental

- Diversos folders e matérias distribuídos aos funcionários e público externo (escolas públicas) de gestão ambiental) responsável pelo meio ambiente, segurança e saúde ocupaciona

- Técnico em gestão ambiental

- Apresentações em PowerPoint de treinamentos ministrados aos funcionários

- Documentos sobre a história da empresa

- Documentos disponíveis no site da empresa

- Política ambiental

- Documentos sobre a história

- Uma visita com duração

- Organização da área de ensino técnico profissionalizante

- Grande porte de quatro horas e trinta minutos

- Dois contatos por telefone

- Três contatos por e-mail
- Coordenador de meio ambiente

- Técnico em gestão ambiental

da empresa

- Relação dos treinamentos e seus conteúdos ministrados aos funcionários

- Documentos disponíveis no site da empresa

- Certificados e prêmios recebidos

- Uma visita com duração de aproximadamente quatro horas

- Três contatos por telefone

- Três contatos por e-mai
- Coordenador de gestão ambiental

ao setor de celulose

- Grande porte
- Engenheiro e gestor de processos e sistemas de gestão

- Política de gestão integrada

- Código de conduta

- Diversos folders e materiais distribuídos aos funcionários

- Documentos sobre a história da empresa

- Documentos disponíveis no site da empresa

- Certificados e prêmios recebidos

- Política ambienta

- Diversos folders e materiais distribuídos aos funcionários de aproximadamente

- Coordenador da área de gestão ambiental no interior da planta industrial

Organização pertencente ao setor de fabricação de painéis de madeira

- Grande porte cinco horas

- Dois contatos por telefone

- Quatro contatos por e-mail
- Supervisor de biodiversidade e relação com a comunidade

- Gestora ambiental responsável pelo controle ambiental da área floresta

- Documentos disponíveis no site da empresa

- Vídeo institucional

- Cartilha sobre cuidados ambientais e de segurança do trabalho

- Apresentação em PowerPoint sobre a história da empresa

- Política do sistema integrado

- Alguns materiais distribuídos aos funcionários

- Documentos sobre a história da empresa

- Documentos disponíveis no site da empresa

- Certificados e prêmios recebidos

- Política ambiental

- Organização que atua

F nos segmentos de nutrição e alimentos

- Grande porte
- Uma visita com duração de aproximadamente três horas

- Dois contatos por

telefone

- Três contatos por e-mail
- Gestor da área da qualidade e ambiental

- Técnico em gestão ambiental aos funcionários

- Documentos sobre a história da empresa

- Documentos disponíveis no site da empresa

- Certificados e prêmios recebidos

- Documentos disponíveis no site da empresa

- Relação dos treinamentos ministrados aos funcionários
- Gerente de qualidade

- Gerente de gestão ambienta de aproximadamente

cinco horas

setor de bens de capital

para o setor de petróleo

- Grande porte
- Um contato por telefone

- Um contato por e-mail 
Quadro 1. Continuação...

\begin{tabular}{|c|c|c|c|c|}
\hline \multirow[b]{2}{*}{ Empresa } & \multirow[b]{2}{*}{ Ramo de atuação/porte } & \multicolumn{3}{|c|}{ Dinâmica da coleta de dados } \\
\hline & & $\begin{array}{c}\text { Observação direta/contatos } \\
\text { realizados }\end{array}$ & Entrevistados & Documentos \\
\hline $\mathrm{H}$ & $\begin{array}{l}\text { - Organização do setor } \\
\text { aeronáutico brasileiro } \\
\text { - Grande porte }\end{array}$ & $\begin{array}{l}\text { - Uma visita com duração } \\
\text { de aproximadamente } \\
\text { quatro horas } \\
\text { - Dois contatos por } \\
\text { telefone } \\
\text { - Um contato por e-mail. }\end{array}$ & $\begin{array}{l}\text { - Gerente de meio ambiente } \\
\text { - Técnico em gestão ambiental }\end{array}$ & $\begin{array}{l}\text { - Certificados e prêmios } \\
\text { - Decebidos } \\
\text { site da empresa } \\
\text { - Relação dos treinamentos } \\
\text { ministrados aos funcionários } \\
\text { - Alguns materiais distribuídos } \\
\text { aos funcionários } \\
\text { - Documentos sobre a história } \\
\text { da empresa } \\
\text { - Política do sistema integrado }\end{array}$ \\
\hline 1 & $\begin{array}{l}\text { - Organização que atua } \\
\text { no mercado de fabricação } \\
\text { e comercialização } \\
\text { de soluções para o } \\
\text { gerenciamento de fios e } \\
\text { cabos } \\
\text { - Grande porte }\end{array}$ & $\begin{array}{l}\text { - Uma visita com duração } \\
\text { de aproximadamente } \\
\text { quatro horas } \\
\text { - Dois contatos por } \\
\text { telefone } \\
\text { - Um contato por e-mail }\end{array}$ & $\begin{array}{l}\text { - Gerente de qualidade } \\
\text { - Gerente de gestão ambiental }\end{array}$ & $\begin{array}{l}\text { - Política ambiental } \\
\text { - Relação de treinamentos } \\
\text { ministrados }\end{array}$ \\
\hline
\end{tabular}

laminados etc. Foi uma das primeiras empresas do Brasil a possuir a certificação do Forest Stewardship Council - FSC.

A empresa E é uma das cinco maiores fabricantes de baterias automotivas e de apoio à geração de energia no país e foi a pioneira na adoção da 1SO 14001 no seu setor de atuação.

A empresa F pertence a um dos maiores grupos do mercado de nutrição humana. Sua atuação abrange os segmentos de achocolatados, biscoitos, cafés, cereais, águas, chocolates, produtos culinários, lácteos e de nutrição infantil.

A empresa $\mathrm{G}$ fornece bombas centrifugas de grande porte. Ela oferece produtos e serviços que atendem aos seguimentos de óleo e gás, refinarias e petroquímicas, distribuição de água e saneamento, geração de energia, papel e celulose, entre outros.

A empresa $\mathrm{H}$ é uma das maiores empresas aeroespaciais do mundo. Ela atua nas áreas de projeto, fabricação, comercialização e pós-venda de aviões para a aviação comercial, executiva e de defesa.

A empresa 1 é uma das líderes do mercado de fabricação e comercialização de soluções para o gerenciamento de fios e cabos utilizando sistemas de amarração, identificação, isolação e proteção.

O Quadro 2 apresenta os principais aspectos do foco do sistema de gestão ambiental ISO 14001 dessas organizações, as características da incorporação da gestão ambiental na estrutura organizacional e as evidências das ações internas e externas quanto à incorporação da gestão ambiental em suas atividades. Com base nessa sistematização, é possível classificar as organizações nos estágios evolutivos da gestão ambiental.

Das nove organizações analisadas, uma (H) está no estágio proativo, duas, no estágio preventivo, tendendo para o proativo (D e F) e seis (A, B, C, E e G) encontram-se no estágio preventivo da gestão ambiental.

A empresa $\mathrm{H}$ encontra-se no estágio mais avançado de gestão ambiental (proativo), pois as questões ambientais são claramente consideradas estratégicas pela organização. A empresa $\mathrm{H}$ quer se tornar líder mundial em gestão ambiental no setor aeronáutico. Nesse sentido, vem contratando consultores e especialistas no tema ambiental para superar os desafios da gestão ambiental em sua planta. Um dos grandes desafios é a reciclagem e recuperação de aviões fabricados pela empresa, uma vez que os materiais utilizados na fabricação das aeronaves possuem robustez, são dúcteis e resistem aos tradicionais processos de reciclagem. A empresa possui critérios ambientais para a seleção de fornecedores (níveis de contaminação dos componentes, ISO 14001 etc.).

Além dessas ações, a empresa $\mathrm{H}$ adota um sistema de certificação ambiental de suas células de manufatura. Um dos principais critérios para uma célula de manufatura atingir o nível máximo (gold) é a necessidade de todos os funcionários da célula se capacitarem em temas ambientais e buscarem alternativas ambientalmente mais adequadas para a produção. Na época da coleta de dados, a empresa $\mathrm{H}$ estava em fase de adoção da metodologia Life Cycle Assessment para redução de impactos ambientais ao longo da cadeia de produção. Como afirma um dos entrevistados: "Queremos ser líderes em gestão ambiental no setor aeronáutico mundial e criar tendência nessa área".

As empresas D e F encontram-se no estágio preventivo com tendência a atingir o nível proativo no médio prazo. 0 foco das atividades de gestão ambiental ainda é em ecoeficiência, buscando a 
Quadro 2. Classificação dos casos nos estágios de gestão ambiental.

\begin{tabular}{|c|c|c|c|c|c|}
\hline Caso & $\begin{array}{c}\text { Foco do sistema de gestão } \\
\text { ambiental 1SO } 14001\end{array}$ & $\begin{array}{c}\text { Estrutura } \\
\text { organizacional }\end{array}$ & Ações internas à empresa & $\begin{array}{l}\text { Ações externas à } \\
\text { empresa }\end{array}$ & $\begin{array}{c}\text { Estágio da } \\
\text { gestão ambiental }\end{array}$ \\
\hline A & $\begin{array}{l}\text { - Ecoeficiência } \\
\text { - Estabelecimento de } \\
\text { metas de redução } \\
\text { do uso de insumos e } \\
\text { materiais dependentes } \\
\text { de recursos naturais, } \\
\text { como energia, água } \\
\text { e papel }\end{array}$ & $\begin{array}{l}\text { - Há uma área de } \\
\text { gestão ambiental } \\
\text { - Início do } \\
\text { envolvimento das } \\
\text { outras áreas da } \\
\text { empresa na gestão } \\
\text { ambiental } \\
\text { - Área de gestão } \\
\text { ambiental } \\
\text { subordinada à } \\
\text { área de gestão da } \\
\text { qualidade }\end{array}$ & $\begin{array}{l}\text { - Promove a coleta } \\
\text { seletiva e de lâmpadas } \\
\text { fluorescentes } \\
\text { - Programa de consumo } \\
\text { consciente } \\
\text { - Programa de coleta de } \\
\text { pilhas e baterias } \\
\text { - Impressão de } \\
\text { documentos em modo } \\
\text { duplex (frente e verso) } \\
\text { - Campanhas para o } \\
\text { aumento da consciência } \\
\text { ambiental dos } \\
\text { funcionários }\end{array}$ & $\begin{array}{l}\text { - Plantação de mudas } \\
\text { de árvores nativas } \\
\text { da Mata Atlântica } \\
\text { para compensar } \\
\text { suas emissões de } \\
\text { GEE (gases do efeito } \\
\text { estufa) } \\
\text { - Informa adotar } \\
\text { critérios ambientais } \\
\text { para avaliar os } \\
\text { fornecedores, mas } \\
\text { não há evidências }\end{array}$ & Preventivo \\
\hline B & $\begin{array}{l}\text { - Ecoeficiência } \\
\text { - Estabelecimento de } \\
\text { metas de redução } \\
\text { do uso de insumos e } \\
\text { materiais dependentes } \\
\text { de recursos naturais, } \\
\text { como a energia, água } \\
\text { e papel }\end{array}$ & $\begin{array}{l}\text { - Há uma área de } \\
\text { gestão ambiental } \\
\text { - Início do } \\
\text { envolvimento das } \\
\text { outras áreas da } \\
\text { empresa na gestão } \\
\text { ambiental }\end{array}$ & $\begin{array}{l}\text { - Programa para a } \\
\text { redução de resíduos } \\
\text { perigosos e substituição } \\
\text { por materiais } \\
\text { alternativos } \\
\text { - Coleta seletiva e } \\
\text { reciclagem } \\
\text { - Programas para reduzir } \\
\text { o uso de recursos } \\
\text { naturais } \\
\text { - Adoção de tecnologias } \\
\text { de fim de processo }\end{array}$ & $\begin{array}{l}\text { - Campanhas } \\
\text { para o aumento } \\
\text { da consciência } \\
\text { ambiental da } \\
\text { comunidade }\end{array}$ & Preventivo \\
\hline C & $\begin{array}{l}\text { - Ecoeficiência } \\
\text { - Estabelecimento de } \\
\text { metas de redução } \\
\text { do uso de insumos e } \\
\text { materiais dependentes } \\
\text { de recursos naturais, } \\
\text { como energia, água } \\
\text { e papel } \\
\text { - Busca de um processo } \\
\text { produtivo mais limpo, } \\
\text { com redução de } \\
\text { produtos químicos } \\
\text { nocivos ao meio } \\
\text { ambiente }\end{array}$ & $\begin{array}{l}\text { - Há uma área de } \\
\text { gestão ambiental } \\
\text { - Início do } \\
\text { envolvimento das } \\
\text { outras áreas da } \\
\text { empresa na gestão } \\
\text { ambiental } \\
\text { - Área de gestão } \\
\text { ambiental é } \\
\text { subordinada à } \\
\text { área de gestão da } \\
\text { qualidade }\end{array}$ & $\begin{array}{l}\text { - Estação de tratamento } \\
\text { dos efluentes } \\
\text { - Controle de efluentes } \\
\text { gasosos } \\
\text { - Gerenciamento de } \\
\text { resíduos sólidos gerados } \\
\text { nos processos } \\
\text { - Monitoramento } \\
\text { ambiental } \\
\text { - Geração de energia } \\
\text { termo-elétrica a partir } \\
\text { de resíduo da produção } \\
\text { - Parte da matéria-prima } \\
\text { possui certificação FSC }\end{array}$ & $\begin{array}{l}\text { - Pretende investir } \\
\text { no mapeamento do } \\
\text { ciclo de vida dos } \\
\text { seus produtos, na } \\
\text { logística reversa } \\
\text { e na reciclagem } \\
\text { para atenuar } \\
\text { seus impactos } \\
\text { ambientais, mas } \\
\text { não há evidência de } \\
\text { ações concretas }\end{array}$ & Preventivo \\
\hline $\mathrm{D}$ & $\begin{array}{l}\text { - Ecoeficiência } \\
\text { - Desenvolvimento de } \\
\text { produtos com menores } \\
\text { impactos ambientais } \\
\text { - Ações de marketing } \\
\text { ambiental } \\
\text { - Catálogo de produtos } \\
\text { ambientalmente } \\
\text { adequados } \\
\text { - Estabelecimento de } \\
\text { metas de redução } \\
\text { do uso de insumos e } \\
\text { materiais dependentes } \\
\text { de recursos naturais, } \\
\text { como energia, água } \\
\text { e papel }\end{array}$ & $\begin{array}{l}\text { - Há uma área de } \\
\text { gestão ambiental } \\
\text { - Início do } \\
\text { envolvimento das } \\
\text { outras áreas da } \\
\text { empresa na gestão } \\
\text { ambiental } \\
\text { - Área de gestão } \\
\text { ambiental } \\
\text { subordinada à } \\
\text { área de gestão da } \\
\text { qualidade } \\
\text { - Planejamento para } \\
\text { a criação de área } \\
\text { que implementará } \\
\text { a LCA }\end{array}$ & $\begin{array}{l}\text { - Áreas de recuperação de } \\
\text { materiais } \\
\text { - Instalação de filtros, } \\
\text { lavadores de gases e } \\
\text { substituição de fornos } \\
\text { a óleo por outros a gás } \\
\text { natural } \\
\text { - Criação da AVAP (área } \\
\text { de vivência ambiental) } \\
\text { - Uso de técnicas no } \\
\text { manejo das áreas de } \\
\text { cultivo } \\
\text { - Certificação FSC para } \\
\text { toda a matéria-prima } \\
\text { usada em seus produtos }\end{array}$ & $\begin{array}{l}\text { - Avaliação dos } \\
\text { fornecedores com } \\
\text { base em critérios } \\
\text { ambientais } \\
\text { - Capacitação dos } \\
\text { vendedores para } \\
\text { expor corretamente } \\
\text { a melhoria } \\
\text { ambiental de seus } \\
\text { produtos }\end{array}$ & $\begin{array}{c}\text { Preventivo } \\
\text { (tendendo ao } \\
\text { proativo) }\end{array}$ \\
\hline E & $\begin{array}{l}\text { - Ecoeficiência } \\
\text { Estabelecimento de } \\
\text { metas de redução } \\
\text { do uso de insumos e } \\
\text { materiais dependentes } \\
\text { de recursos naturais, } \\
\text { como energia, água } \\
\text { e papel } \\
\text { - Atendimento à } \\
\text { legislação brasileira } \\
\text { sobre baterias } \\
\text { automotivas }\end{array}$ & $\begin{array}{l}\text { - Há uma área de } \\
\text { gestão ambiental } \\
\text { - A área de gestão } \\
\text { ambiental possui } \\
\text { certo isolamento } \\
\text { na estrutura } \\
\text { organizacional } \\
\text { - Início do } \\
\text { envolvimento das } \\
\text { outras áreas da } \\
\text { empresa na gestão } \\
\text { ambiental }\end{array}$ & $\begin{array}{l}\text { - Estação de tratamento } \\
\text { de efluentes } \\
\text { - Gerenciamento de } \\
\text { resíduos sólidos gerados } \\
\text { nos processos } \\
\text { - Instalação de } \\
\text { exaustores, lavadores de } \\
\text { gases e filtros } \\
\text { - Monitoramento de } \\
\text { lençol freático }\end{array}$ & $\begin{array}{l}\text { - Doações para } \\
\text { eventos de } \\
\text { conscientização } \\
\text { ambiental da } \\
\text { comunidade } \\
\text { - Participação } \\
\text { de premiações } \\
\text { oferecidas pela } \\
\text { comunidade pelo } \\
\text { desempenho } \\
\text { ambiental }\end{array}$ & Preventivo \\
\hline
\end{tabular}


Quadro 2. Continuação...

\begin{tabular}{|c|c|c|c|c|c|}
\hline Caso & $\begin{array}{l}\text { Foco do sistema de gestão } \\
\text { ambiental ISO } 14001\end{array}$ & $\begin{array}{c}\text { Estrutura } \\
\text { organizacional }\end{array}$ & Ações internas à empresa & $\begin{array}{l}\text { Ações externas à } \\
\text { empresa }\end{array}$ & $\begin{array}{c}\text { Estágio da } \\
\text { gestão ambiental }\end{array}$ \\
\hline $\mathrm{F}$ & $\begin{array}{l}\text { - Ecoeficiência } \\
\text { - Estabelecimento de } \\
\text { metas de redução } \\
\text { do uso de insumos e } \\
\text { materiais dependentes } \\
\text { de recursos naturais, } \\
\text { como energia, água } \\
\text { e papel } \\
\text { - Aderiu à Carta das } \\
\text { Empresas para o } \\
\text { Desenvolvimento } \\
\text { Sustentável } \\
\text { - Busca a adoção de } \\
\text { princípios do Pacto } \\
\text { Global da ONU } \\
\text { - Foco na gestão da } \\
\text { água, principal insumo } \\
\text { do processo produtivo }\end{array}$ & $\begin{array}{l}\text { - Há uma área de } \\
\text { gestão ambiental } \\
\text { - Comitê consultivo } \\
\text { com consultores } \\
\text { e especialistas } \\
\text { na área de } \\
\text { sustentabilidade } \\
\text { - Início do } \\
\text { envolvimento das } \\
\text { outras áreas da } \\
\text { empresa na gestão } \\
\text { ambiental } \\
\text { - Área de gestão } \\
\text { ambiental } \\
\text { subordinada à } \\
\text { área de gestão da } \\
\text { qualidade }\end{array}$ & $\begin{array}{l}\text { - Campanhas internas } \\
\text { para uso eficiente da } \\
\text { água } \\
\text { - Redução do consumo } \\
\text { de água por unidade de } \\
\text { produto consumido } \\
\text { - Adoção de tecnologias } \\
\text { ambientais para } \\
\text { reaproveitamento de } \\
\text { água } \\
\text { - Programa de } \\
\text { reaproveitamento e } \\
\text { reciclagem de resíduos } \\
\text { - Campanhas para o uso } \\
\text { eficiente de energia } \\
\text { elétrica } \\
\text { - Programa de redução de } \\
\text { emissões de gases }\end{array}$ & $\begin{array}{l}\text { - Aspectos ambientais } \\
\text { incluídos na seleção } \\
\text { e desenvolvimento } \\
\text { de fornecedores } \\
\text { - Parceria com } \\
\text { empresas } \\
\text { desenvolvedoras de } \\
\text { tecnologias para } \\
\text { o uso eficiente da } \\
\text { água no processo } \\
\text { produtivo }\end{array}$ & $\begin{array}{l}\text { Preventivo } \\
\text { (tendendo a } \\
\text { proativo) }\end{array}$ \\
\hline G & $\begin{array}{l}\text { - Ecoeficiência } \\
\text { - Estabelecimento de } \\
\text { metas de redução } \\
\text { do uso de insumos e } \\
\text { materiais dependentes } \\
\text { de recursos naturais, } \\
\text { como energia, água } \\
\text { e papel } \\
\text { - Foco na legislação } \\
\text { ambiental }\end{array}$ & $\begin{array}{l}\text { - Há uma área de } \\
\text { gestão ambiental } \\
\text { - Área de gestão } \\
\text { ambiental } \\
\text { subordinada à } \\
\text { área de gestão da } \\
\text { qualidade } \\
\text { - Fraco envolvimento } \\
\text { das demais } \\
\text { áreas na gestão } \\
\text { ambiental }\end{array}$ & $\begin{array}{l}\text { - Prevenção à poluição } \\
\text { - Controles ambientais, } \\
\text { inclusive fazendo uso } \\
\text { de indicadores (controle } \\
\text { de combustíveis, água e } \\
\text { emissões) } \\
\text { - Uso de softwares que } \\
\text { permitem uma melhor } \\
\text { gestão de documentos } \\
\text { e comparações dos } \\
\text { impactos ambientais } \\
\text { versus legislação } \\
\text { ambiental. }\end{array}$ & $\begin{array}{l}\text { - Atendimento } \\
\text { aos requisitos } \\
\text { ambientais do } \\
\text { principal comprador } \\
\text { de seus produtos, } \\
\text { uma grande empresa } \\
\text { brasileira do setor de } \\
\text { petróleo }\end{array}$ & Preventivo \\
\hline $\mathrm{H}$ & $\begin{array}{l}\text { - Desenvolvimento } \\
\text { de tecnologias mais } \\
\text { limpas para o setor } \\
\text { aeronáutico brasileiro } \\
\text { Implementação da LCA } \\
\text { - Certificação ambiental } \\
\text { das células de } \\
\text { produção } \\
\text { Ecoeficiência }\end{array}$ & $\begin{array}{l}\text { - Há uma área de } \\
\text { - gestão ambiental } \\
\text { ambiental } \\
\text { subordinada à } \\
\text { área de gestão da } \\
\text { qualidade } \\
\text { - Cada célula } \\
\text { de produção } \\
\text { se envolve } \\
\text { diretamente com } \\
\text { os assuntos de } \\
\text { gestão ambiental } \\
\text { - Envolvimento de } \\
\text { todas as áreas na } \\
\text { gestão ambiental } \\
\text { - Criação de uma } \\
\text { subárea para a LCA }\end{array}$ & $\begin{array}{l}\text { - Programa de coleta } \\
\text { seletiva } \\
\text { - Gerenciamento de } \\
\text { resíduos industriais } \\
\text { - Programa de } \\
\text { monitoramento de } \\
\text { efluentes industriais } \\
\text { - Sistema de reuso de } \\
\text { águas } \\
\text { - Classificação e } \\
\text { certificação de células } \\
\text { de produção no quesito } \\
\text { gestão ambiental }\end{array}$ & $\begin{array}{l}\text { - Programa de } \\
\text { avaliação ambiental } \\
\text { de fornecedores } \\
\text { - Programa de } \\
\text { desenvolvimento } \\
\text { ambiental da cadeia } \\
\text { de fornecimento } \\
\text { - Avaliação do } \\
\text { impacto ambiental } \\
\text { ao longo da cadeia } \\
\text { - Planejamento de } \\
\text { implementação } \\
\text { da Life Cycle } \\
\text { Assessment, já com } \\
\text { evidências concretas } \\
\text { - Adoção do princípio } \\
\text { de responsabilidade } \\
\text { estendida } \\
\text { do produtor } \\
\text { (recuperação de } \\
\text { aeronaves antigas) }\end{array}$ & Proativo \\
\hline 1 & $\begin{array}{l}\text { - Ecoeficiência } \\
\text { - Estabelecimento de } \\
\text { metas de redução } \\
\text { do uso de insumos e } \\
\text { materiais dependentes } \\
\text { de recursos naturais, } \\
\text { como energia, água } \\
\text { e papel }\end{array}$ & $\begin{array}{l}\text { - Há uma área de } \\
\text { gestão ambiental } \\
\text { - Área de gestão } \\
\text { ambiental } \\
\text { subordinada à } \\
\text { área de gestão da } \\
\text { qualidade }\end{array}$ & $\begin{array}{l}\text { - Emprego de tecnologias } \\
\text { ambientais } \\
\text { - Avaliação dos impactos } \\
\text { dos produtos e } \\
\text { processos no meio } \\
\text { ambiente através } \\
\text { do monitoramento } \\
\text { contínuo } \\
\text { - Os produtos são } \\
\text { projetados e fabricados } \\
\text { com materiais que } \\
\text { permitem a reciclagem }\end{array}$ & $\begin{array}{l}\text { - Maior aproximação } \\
\text { com os fornecedores } \\
\text { de bens de capital } \\
\text { para reduzir o } \\
\text { consumo de energia } \\
\text { - Engajamento em } \\
\text { projetos para o } \\
\text { desenvolvimento } \\
\text { de plásticos } \\
\text { biodegradáveis, mas } \\
\text { sem sucesso }\end{array}$ & Preventivo \\
\hline
\end{tabular}


maior produtividade dos insumos naturais. Isso é particularmente relevante para a empresa $\mathrm{F}$, cujos produtos são significativamente dependentes da água. A empresa $\mathrm{D}$ é líder na produção de chapas de madeira ambientalmente adequadas e 100\% da madeira utilizada é proveniente de manejo florestal sustentável (FSC). Em ambas as empresas, as áreas de gestão ambiental interagem com as demais áreas da empresa. Um exemplo é a participação da área de gestão ambiental na criação de estratégias de marketing ambiental na empresa D. As empresas D e $\mathrm{F}$ avaliam seus fornecedores com base em critérios ambientais, sendo que a empresa D planeja, no médio prazo, implementar a metodologia Life Cycle Assessment.

As empresas A, B, C, E, G e 1 estão no estágio preventivo. A preocupação exclusiva do sistema de gestão ambiental dessas empresas é a busca por ecoeficiência, isto é, reduzir o consumo de insumos como água, energia e outros durante o processo produtivo. A área de gestão ambiental dessas empresas tende a atuar de forma isolada, sem significativa influência sobre a decisão de outras áreas organizacionais. Como um dos entrevistados da empresa $\mathrm{G}$ afirmou: "se a minha empresa estiver cumprindo a legislação, tudo estará bem. Nós já temos poder de mercado suficiente para não depender do nosso desempenho ambiental. Mesmo assim, buscamos redução de consumo de água e energia”.

\subsection{Treinamento ambiental}

Para a análise das características de treinamento ambiental nas organizações analisadas, foram consideradas as fases do processo de treinamento sugeridas pela norma INTERNATIONAL...(2001), bem como algumas atividades de treinamento ambiental recomendadas pela INTERNATIONAL...(2004) (como, por exemplo, treinamento a terceiros, treinamento a todos os funcionários etc.)

Os temas mais abordados nas sessões de treinamento ambiental para o conjunto dos casos são: política ambiental, processo de auditoria ambiental, sistema de gestão ambiental, impactos e aspectos ambientais para cada cargo, ecoeficiência e coleta seletiva. Verificou-se uma distinção entre os temas abordados nas sessões de treinamento ambiental, segundo o nível hierárquico dos participantes. Enquanto os temas citados são comuns a todos os níveis hierárquicos, verificou-se que a alta administração e os funcionários da área de gestão ambiental tinham contato com temas emergentes em gestão ambiental, tais como mudança climática, protocolo de Kyoto, créditos de carbono e marketing verde. Esses temas foram especialmente abordados nas empresas $\mathrm{H}$, D e F.

Verificou-se que a maior parte das empresas (exceto A e E) compara as competências ambientais já desenvolvidas pelos funcionários com aquelas requeridas pelo cargo (matriz de competências) para gerar informações para o planejamento do treinamento ambiental que será oferecido. Algumas empresas apresentaram dificuldades para criar programas e elencar os conteúdos para as sessões de treinamento ambiental (A, B e 1). A maior parte das empresas possui registros que certificam o oferecimento de treinamento ambiental a todos os funcionários, mas algumas empresas alegaram dificuldade em cumprir essa recomendação da ISO 14001 (A, B e C). Uma das causas dessa dificuldade reside na elevada taxa de turnover (rotatividade) dos funcionários. Como um dos entrevistados informou: "Nós damos treinamento ambiental hoje e amanhã o funcionário já está fora da empresa. Todo o esforço de treinamento ambiental é perdido".

A empresa $G$ evidenciou outra dificuldade do treinamento ambiental: a falta de conhecimento técnico e sobre desempenho ambiental dos equipamentos do processo produtivo da empresa. Essa falta de conhecimento prejudicou os indicadores ambientais da empresa. Segundo um entrevistado: "Durante a crise financeira de 2008 nós reduzimos um turno de produção, mas não sabíamos lidar com os equipamentos nessa situação. Assim começamos a usar os equipamentos de forma interrompida, porque não havia volume de produção suficiente para deixá-los ligados continuamente. Isso prejudicou os indicadores do nosso sistema de gestão ambiental, pois o consumo de energia aumentou muito. Os fornecedores não ofereceram treinamento ambiental para nós”.

Quanto à execução do treinamento, há predominância de seu oferecimento dentro da empresa (in-house) e apenas algumas organizações que já possuem sistemas de universidade corporativa oferecem o treinamento ambiental à distância (A, H e l). Por fim, na fase de avaliação, percebe-se que a maior parte das empresas registra os dados do treinamento ambiental e verifica a sua eficácia principalmente por provas e testes ao final da sessão de treinamento ambiental. Entretanto, apenas a empresa $\mathrm{H}$ avalia a satisfação do funcionário (treinado) com o intuito de melhorar as próximas sessões de treinamento ambiental da empresa.

0 Quadro 3 sistematiza o nível de adoção de atividades de treinamento ambiental para os casos analisados. É possível verificar que a empresa $\mathrm{H}$ (estágio proativo de gestão ambiental) é aquela que apresenta maior nível de adequação às atividades de 
Quadro 3. Sistematização dos aspectos gerais de treinamento ambiental das empresas estudadas.

\begin{tabular}{|c|c|c|c|c|c|c|c|c|c|c|}
\hline $\begin{array}{l}\text { Fases do processo } \\
\text { de treinamento } \\
\text { ambiental segundo } \\
\text { a ISO } 14001 \text { e a } 1 S 0 \\
10015\end{array}$ & Atividades do treinamento & $A$ & B & C & $\mathrm{D}$ & $\mathrm{E}$ & $\mathrm{F}$ & G & $\mathrm{H}$ & 1 \\
\hline \multirow{2}{*}{$\begin{array}{l}\text { Definição das } \\
\text { necessidades } \\
\text { de treinamento } \\
\text { ambiental }\end{array}$} & $\begin{array}{l}\text { Levantamento das } \\
\text { necessidades de treinamento }\end{array}$ & Sim & Sim & Sim & Sim & Sim & Sim & Sim & Sim & Sim \\
\hline & $\begin{array}{l}\text { Estabelecimento de matriz } \\
\text { de competência para cada } \\
\text { cargo e função dentro da } \\
\text { empresa }\end{array}$ & Não & Sim & Sim & Sim & Não & Sim & Sim & Sim & Sim \\
\hline \multirow{4}{*}{$\begin{array}{l}\text { Projeto e } \\
\text { planejamento } \\
\text { do treinamento } \\
\text { ambiental }\end{array}$} & $\begin{array}{l}\text { Atribuição, papéis, } \\
\text { responsabilidades para o } \\
\text { processo de treinamento } \\
\text { ambiental }\end{array}$ & Sim & Sim & Sim & Sim & Sim & Sim & Sim & Sim & Sim \\
\hline & Treinamento para terceiros & Sim & Sim & Sim & Sim & $\operatorname{Sim}$ & Sim & Sim & Sim & Sim \\
\hline & $\begin{array}{l}\text { Estabelecimento do } \\
\text { programa de treinamento }\end{array}$ & Não & Não & Sim & Sim & Sim & Sim & Sim & Sim & Não \\
\hline & $\begin{array}{l}\text { Treinamento a todos os } \\
\text { funcionários independente } \\
\text { do cargo ou a função que } \\
\text { ocupa }\end{array}$ & Não & Não & Não & Sim & Sim & Sim & Sim & Sim & Sim \\
\hline \multirow{2}{*}{$\begin{array}{l}\text { Execução do } \\
\text { treinamento } \\
\text { ambiental }\end{array}$} & $\begin{array}{l}\text { Treinamentos presenciais in } \\
\text { loco na empresa } \\
\text { (in-house) }\end{array}$ & Sim & $\operatorname{Sim}$ & Sim & Sim & Sim & Sim & Sim & Sim & Sim \\
\hline & $\begin{array}{l}\text { Treinamentos à distância/ } \\
\text { fora da empresa }\end{array}$ & Sim & Não & Não & Não & Não & Não & Não & Sim & Não \\
\hline \multirow{3}{*}{$\begin{array}{l}\text { Avaliação dos } \\
\text { resultados do } \\
\text { treinamento } \\
\text { ambiental }\end{array}$} & $\begin{array}{l}\text { Verificação da eficácia do } \\
\text { treinamento }\end{array}$ & $\mathrm{Sim}$ & Sim & $\mathrm{Sim}$ & Sim & $\mathrm{Sim}$ & Sim & Não & $\mathrm{Sim}$ & Sim \\
\hline & Registros dos treinamentos & Sim & Sim & Sim & Sim & Sim & Sim & Sim & Sim & Sim \\
\hline & $\begin{array}{l}\text { Avaliação da satisfação do } \\
\text { treinado }\end{array}$ & Não & Sim & Não & Não & Não & Não & Não & Sim & Não \\
\hline
\end{tabular}

treinamento ambiental recomendadas pela ISO 14001 e ISO 10015. Já as empresas D e F (classificadas no estágio preventivo de gestão ambiental, rumo ao estágio de proatividade) são aquelas que, após a empresa $\mathrm{H}$, mais adotam atividades de treinamento ambiental recomendadas pela International...(2004) e International...(2001). Já as empresas A, B, C, E, G e 1 (estágio preventivo de gestão ambiental) são as que adotam práticas recomendadas pela International... (2004) e International...(2001) com menor intensidade, quando se comparam todos os casos analisados.

Algumas empresas apresentam práticas que as diferenciam das demais. 0 Quadro 4 destaca essas iniciativas, que podem ser consideradas "boas práticas". Essas práticas não são explicitamente recomendadas pela ISO 14001 e ISO 10015, mas podem contribuir para os propósitos de melhoria do treinamento ambiental.

É curioso notar que, exceto na empresa $\mathrm{H}$, as demais boas práticas são utilizadas por empresas que não atendem a todas as atividades de treinamento ambiental recomendadas pela International... (2004) e International...(2001) e consideradas nesta pesquisa (Quadro 3). Devem-se destacar as práticas de conscientização ambiental adotadas pela empresa A. Essa empresa, no entanto, não atende às fases para consolidar o processo de treinamento ambiental conforme recomendado pela International... (2004) e International...(2001). 0 mesmo tende a ocorrer com as empresas B, C e G: as firmas adotam práticas diferenciadas (Quadro 4) para favorecer a conscientização e o treinamento ambiental ao mesmo tempo em que ignoram atividades fundamentais para a consolidação de um adequado processo de treinamento ambiental (Quadro 3). Já as empresas com segundo maior nível de adoção das atividades de treinamento ambiental recomendadas pela ISO 14001 e ISO 10015 (empresas D e F) não apresentaram evidências de que possuem práticas boas e diferenciadas de treinamento ambiental. Assim, as empresas D e F parecem ter se concentrado em consolidar o processo de treinamento ambiental antes de adotar práticas diferenciadas de treinamento ambiental.

\subsection{Análise comparativa entre os resultados de treinamento e gestão ambiental}

Percebe-se que há evidências de uma coevolução entre o estágio evolutivo de gestão ambiental e o nível de adoção das atividades de treinamento ambiental recomendadas pela ISO 14001 e ISO 10015. Verificou-se que a empresa com maior nível de desenvolvimento de gestão ambiental é a mesma 
Quadro 4. Boas práticas de treinamento ambiental das empresas estudadas.

\begin{tabular}{|c|c|}
\hline Empresa & $\begin{array}{l}\text { Práticas boas/diferenciadas de treinamento } \\
\text { ambiental }\end{array}$ \\
\hline A & $\begin{array}{l}\text { - Formação de agentes internos multiplicadores } \\
\text { das causas ambientais } \\
\text { - Campanhas corporativas como "plante uma } \\
\text { árvore", com distribuição de folders e sementes } \\
\text { de árvore } \\
\text { - Premiação de quem participa das campanhas } \\
\text { com camisetas, sacolas e brindes comemorativos } \\
\text { - Concurso interno "A empresa e o Meio } \\
\text { Ambiente", que aborda temas relacionados ao } \\
\text { meio ambiente para funcionários, filhos e netos, } \\
\text { com redações, fotos, poemas e pinturas. }\end{array}$ \\
\hline B & $\begin{array}{l}\text { - Participação em feira internacional para } \\
\text { intercâmbio de boas práticas socioambientais }\end{array}$ \\
\hline C & $\begin{array}{l}\text { - Quando se trata de treinamentos especializados, } \\
\text { a empresa contrata consultores para realiza-los }\end{array}$ \\
\hline $\mathrm{D}$ & • Não há \\
\hline$E$ & • Não há \\
\hline $\mathrm{F}$ & • Não há \\
\hline G & $\begin{array}{l}\text { - Mensalmente ocorre uma integração, inclusive } \\
\text { com terceiros, para troca de conhecimentos } \\
\text { ambientais } \\
\text { - Anualmente é realizado um encontro entre } \\
\text { todas as filiais da empresa, com o intuito de } \\
\text { compartilhar experiências ambientais }\end{array}$ \\
\hline $\mathrm{H}$ & $\begin{array}{l}\text { - Anualmente há um workshop de todas as } \\
\text { unidades do grupo empresarial para discutir } \\
\text { experiências e melhores práticas em gestão } \\
\text { ambiental } \\
\text { - Treinamento ambiental e certificação das células } \\
\text { de manufatura }\end{array}$ \\
\hline 1 & • Não há \\
\hline
\end{tabular}

empresa com maior nível de adoção das atividades de treinamento ambiental (empresa $\mathrm{H}$ ); as empresas com o segundo melhor nível de gestão ambiental (D e F) são aquelas que apresentam também o segundo melhor nível de atendimento às atividades de treinamento ambiental recomendadas pela ISO 14001 e ISO 10015. Por fim, as empresas A, B, C, E, G e l, que apresentaram os menores desempenhos em gestão ambiental, apresentaram também os menores níveis de adoção de atividades do processo de treinamento ambiental consideradas nesta pesquisa.

Esses resultados confirmam as afirmações de Sarkis, Gonzalez-Torres e Adenso-Diaz (2010) sobre a influência positiva do treinamento ambiental na adoção de práticas de gestão ambiental nas organizações, adicionando evidências de que essa influência positiva tende a ser acompanhada por um comportamento coevolutivo entre treinamento ambiental e gestão ambiental nas organizações analisadas.

\section{Conclusões}

Esta pesquisa teve como objetivos identificar as principais características do treinamento ambiental em empresas de diferentes setores econômicos, verificar se há relação entre o treinamento ambiental e o estágio evolutivo da gestão ambiental nas organizações e detectar as boas práticas de treinamento ambiental nos casos analisados. A partir de um estudo de múltiplos casos com nove empresas foi possível alcançar os objetivos inicialmente propostos.

0 resultado mais relevante desta pesquisa é a identificação de coevolução entre o nível de treinamento ambiental e o estágio evolutivo de gestão ambiental dos casos analisados. Embora o estado da arte sobre o tema (BRÍO; FERNÁNDEZ; JUNQUERA, 2007; DAILY; BISHOP; STEINER, 2007; BRÍO; JUNQUERA; ORDIZ, 2008; JABBOUR; SANTOS; NAGANO, 2010; UNNIKRISHNAN; HEGDE, 2007; SARKIS; GONZALEZ-TORRES; ADENSO-DIAZ, 2010) tenha ressaltado a relevância do treinamento ambiental para uma adequada gestão ambiental, esta pesquisa contribui de forma mais específica ao produzir evidências de um comportamento coevolutivo dessas práticas nas organizações, ainda que pesem as limitações deste estudo.

Outra contribuição dos resultados desta pesquisa indica que os temas de treinamento ambiental mais frequentes nas empresas analisadas são similares aos apontados pela literatura especializada: política ambiental, ecoeficiência e reciclagem. Além disso, constatou-se que alguns temas de treinamento ambiental, sobre questões emergentes de gestão ambiental, tendem a atingir apenas membros da alta administração ou os responsáveis pela gestão ambiental. Como exemplo de temas tem-se mudança climática, protocolo de Kyoto e créditos de carbono. 0 interesse nesses temas pode ser justificado pelo mercado de créditos de carbono brasileiro que surgiu com o Protocolo de Kyoto.

Verificou-se que algumas empresas não aderem por completo às atividades para um processo de treinamento ambiental de excelência, conforme recomendações da International...(2004) e International...(2001), mas ao mesmo tempo oferecem aos seus funcionários uma série diferenciada de práticas de conscientização ambiental que pode influenciar positivamente o treinamento ambiental. Este é o caso, por exemplo, das organizações A, B, C e G. Essas empresas parecem ter "pulado etapas" do processo de treinamento ambiental: em vez de consolidarem o processo e as características de treinamento ambiental, começaram a alocar recursos para o oferecimento de práticas diferenciadas de conscientização ambiental, mas esqueceram-se de algumas atividades fundamentais no oferecimento de treinamento ambiental, recomendadas pelas $1 \mathrm{SO}$ 14001 e ISO 10015.

Quanto às atividades do treinamento ambiental adotadas pelas empresas, cabe ressaltar que algumas 
empresas apresentam dificuldades em avaliar os resultados do treinamento, conforme já havia sido identificado por Perron, Côté e Duffy (2006) para empresas canadenses. Outra barreira observada foi a dificuldade de se formular programas temáticos para o processo de treinamento ambiental. Essa dificuldade poderia ser superada com uma maior aproximação entre setor empresarial e universidades, conforme propõem Cloquell-Ballester et al. (2008).

Os resultados chamam a atenção para a importância dos fornecedores de tecnologias para o processo produtivo como fonte de treinamento ambiental. Para as empresas que adquirem essas tecnologias, a divulgação de informações sobre os impactos ambientais gerados pelos equipamentos e sobre como operá-los em situações de exceção é importante. Essa observação mostrou-se válida especialmente para a empresa G, confirmando que os fornecedores de tecnologias para o processo produtivo podem ser fontes relevantes de treinamento ambiental para as empresas, conforme proposto por Unnikrishnan e Hegde (2007). Observou-se também a necessidade de criar estratégias para lidar com a elevada taxa de turnover (rotatividade dos funcionários) de algumas empresas, que tende a prejudicar a meta de oferecimento de treinamento ambiental a todos os funcionários.

0 conjunto desses resultados gera implicações para os dirigentes empresariais e para os pesquisadores em gestão ambiental. Para os dirigentes empresariais, esta pesquisa evidencia que: o treinamento ambiental tende a influenciar o nível de desenvolvimento da gestão ambiental; deve-se evitar "pular etapas" do processo de treinamento ambiental, a exemplo da falta de avaliação da satisfação dos funcionários treinados. Já para os pesquisadores em treinamento ambiental esta pesquisa oferece evidências reais sobre o tema em um campo de investigação tradicionalmente teórico (DAILY; HUANG, 2001; FERNÁNDEZ; JUNQUERA; ORDIZ, 2003; GOVINDARAJULU; DAILY, 2004; JABBOUR; SANTOS, 2008) e confirma algumas conclusões de pesquisas anteriores sobre treinamento ambiental, além de ressaltar a importância da academia para ajudar o setor empresarial na melhoria do processo de treinamento ambiental, conforme Cloquell-Ballester et al. (2008). Além disso, apresenta evidências de coevolução entre os temas de treinamento ambiental e gestão ambiental.

Esta pesquisa apresenta limitações metodológicas e de recorte geográfico. Metodologicamente, são necessários novos estudos de caso e pesquisas com teste de hipóteses sobre o tema de treinamento ambiental. Por exemplo, pesquisas quantitativas do tipo survey poderiam testar a hipótese de coevolução entre treinamento ambiental e gestão ambiental para uma amostra estatisticamente representativa de empresas. Outra sugestão de investigação seria pesquisar as contribuições do treinamento ambiental para que as organizações atinjam um padrão de desempenho mais sustentável (econômico, ambiental e social), conforme propõe, por exemplo, a Associação Brasileira de Engenharia de Produção - ABEPRO.

\section{Referências}

AGENDA 21. O que é Agenda 21? 1992. Disponível em: $<$ www.ambiente.sp.gov.br/agenda21.php>. Acesso em: 25 jan. 2010.

AZZONE G.; BERTELE, U. Exploiting green strategies for competitive advantage. Long Range Planning, v. 27, n. 6, p. 69-81, 1994. http://dx.doi. org/10.1016/0024-6301(94)90165-1

AZZONE, G.; BERTELÈ, U.; NOCl, G.; At last we are creating environmental strategies which work. Long Range Planning, v. 30, n. 4, p. 562-571, 1997. http://dx.doi. org/10.1016/S0024-6301(97)00035-6

BEARD, C. Environmental training: emerging products. Industrial and Commercial Training, v. $28, \quad$ n. $5, \quad$ p. $18-23,1996$. http://dx.doi. org/10.1108/00197859610122072

BERRY, M. A.; RONDINELLl, D. A. Proactive environmental management: A new industrial revolution. The Academy of Management Executive, v. 12, n. 2, p. 38-50, 1998. http://dx.doi.org/10.5465/AME.1998.650515

BOIRAL, 0. Global warming: should companies adopt a proactive strategy? Long Range Planning, v. 39, p. 315-330, 2006. http://dx.doi.org/10.1016/j. Irp.2006.07.002

BORRI, F.; BOCCALETTI, G. From total quality management to total quality environmental management. The TQM Magazine, v. 7, n. 5, p. 38-42, 1995. http://dx.doi. org/10.1108/09544789510098614

BRÍO, J. A.; FERNÁNDEZ, E.; JUNQUERA, B. Management and employee involvement in achieving an environmental action-based competitive advantage: an empirical study. International Journal of Human Resource Management, v. 18, 4, p. 491-522, 2007. http://dx.doi. org/10.1080/09585190601178687

BRÍO, J.A.; JUNQUERA, B.; ORDIZ, M. Human resources in advanced environmental approaches - a case analysis. International Journal of Production Research, v. 46, n. 21, p. 6029-6053, 2008. http://dx.doi. org/10.1080/00207540701352094

CLOQUELL-BALLESTER, V. et al. Environmental education for small- and medium-sized enterprises: methodology and e-learning in the Valencian region. Journal of Environmental Management, v. 87, p. 507-520, 2008. PMid:17395365. http://dx.doi.org/10.1016/j. jenvman.2007.01.041

COLE, M. A.; ELLIOTT, R. J. R.; STROBL, E. The environmental performance of firms: The role of foreign ownership, training, and experience. Ecological Economics, v. 65, p. 538-546, 2008. http://dx.doi.org/10.1016/j. ecolecon.2007.07.025

DAILY, B.; HUANG, S. Achieving sustainability through attention to human resource factors in environmental management. International Journal of Operations \& Production Management, v. 21, n. 12, p. 1539-1552, 2001. http://dx.doi.org/10.1108/01443570110410892 
DAILY, B. F.; BISHOP, J.; STEINER R. The Mediating Role of EMS Teamwork as it pertains to HR Factors and Perceived Environmental Performance. Journal of Applied Business Research, v. 23, n. 1, p. 95-109, 2007.

EISENHARDT, K. M. Building theories from case study research. The Academy of Management Review, v. 14, n. 4, p. 532-550, 1989.

FERNÁNDEZ, E.; JUNQUERA, B.; ORDIZ, M. Organizational culture and human resources in the environmental issue: a review of literature. International Journal of Human Resource Management, v. 14, n. 4, p. 634-656, 2003. http://dx.doi.org/10.1080/0958519032000057628

GONZÁlES-BENITO, J.; GONZÁLES-BENITO, O. A review of de determinant factors of environmental proactivity. Business Strategy and the Environment, v. 15, n. 2, p. 87-102, 2006. http://dx.doi.org/10.1002/bse.450

GOVINDARAJULU, N.; DAILY, B. F. Motivating employees for environmental improvement. Industrial Management \& Data Systems, v. 104, n. 4, p. 364-372, 2004. http:// dx.doi.org/10.1108/02635570410530775

HADEN, S. S. P.; OYLER, J. D.; HUMPHREYS, J. H. Historical, practical, and theoretical perspectives on green management: An exploratory analysis. Management Decision, v. 47, n. 7, p. 1041-55, 2009. http://dx.doi. org/10.1108/00251740910978287

HALE, M. Training for environmental technologies and environmental management. Journal of Cleaner Production, v. 3, n. 1-2, p. 19-23, 1995. http://dx.doi. org/10.1016/0959-6526(95)00060-R

HAMMER, B. Cleaner production training in Asia: experience from the ASEAN environmental impact project. Journal of Cleaner Production, v. 7, p. 75-81, 1999. http://dx.doi. org/10.1016/S0959-6526(98)00044-4

HUNT, C. B.; AUSTER, E. R. Proactive environmental management: avoiding the toxic trap. MIT Sloan Management Review, v. 31, n. 2, p. 7-18, 1990.

INTERNATIONAL ORGANIZATION FOR STANDARDIZATION - 1SO. ISO 10015/2001: Gestão da qualidade - Diretrizes para treinamento. Rio de Janeiro, 2001.

INTERNATIONAL ORGANIZATION FOR STANDARDIZATION - 1SO. ISO 14001/2004: Sistema de Gestão Ambiental. Especificação e diretrizes para uso. Rio de Janeiro, 2004.

JABBOUR, A. B. L. S.; JABBOUR, C. J. C. Are supplier selection criteria going green? Case studies of companies in Brazil. Industrial Management \& Data Systems, v. 109, n. 4, 477-489, 2009. http://dx.doi. org/10.1108/02635570910948623

JABBOUR, C. J. C.; SANTOS, F. C. A. Relationships between human resource dimensions and environmental management in companies: proposal of a model. Journal of Cleaner Production, v. 16, n. 1, p. 51-58, 2008. http:// dx.doi.org/10.1016/j.jclepro.2006.07.025

JABBOUR, C. J. C. Non-linear pathways of corporate environmental management: a survey of ISO 14001-certified companies in Brazil. Journal of Cleaner Production, v. 18, n. 12, p. 1222-1225, 2010. http://dx.doi.org/10.1016/j.jclepro.2010.03.012

JABBOUR, C. J. C.; SANTOS, F. C. A.; NAGANO, M. S. Contributions of HRM throughout the stages of environmental management: methodological triangulation applied to companies in Brazil. International Journal of Human Resource Management, v. . 21, n. 7, p. 1049-1089, 2010.
MARSHALL, M. E.; MAYER, D. W. Environmental training: 1t's good business. Business Horizons, v. 35 n. 2, p. 54-57, 1992. http://dx.doi.org/10.1016/ S0007-6813(05)80197-1

MASSOUD, M. A. et al. Drivers, barriers and incentives to implementing environmental management systems in the food industry: a case from Lebanon. Journal of Cleaner Production, v. 18, p. 200-219, 2010. http:// dx.doi.org/10.1016/j.jclepro.2009.09.022

MOLINA-AZORIN, J. F. et al. Green management and financial performance: a literature review. Management Decision, v. 47, n. 7, p. 1080-1100, 2009. http://dx.doi. org/10.1108/00251740910978313

MULLER-CARMEM, M. et al. Green Human Resource Management. Zeitschrift für Personalforschung, v. 24, n. 1, p. 95-96, 2010.

O'BRIEN, C. 1999. Sustainable production - a new paradigm for a new millennium. International Journal of Production Economics, v. 60, n. 61, p. 1-7, 1999. http:// dx.doi.org/10.1016/S0925-5273(98)00126-1

PERRON, G. M.; CÔTE, R. P.; DUFFY, J. F. Improving environmental awareness training in business. Journal of Cleaner Production, v. 14, n. 6-7, p. 551-562, 2006. http://dx.doi.org/10.1016/j.jclepro.2005.07.006

PIGOSSO D. C. A. et al. Ecodesign methods focused on remanufacturing. Journal of Cleaner Production, v. 18, p. 21-31, 2010. http://dx.doi.org/10.1016/j. jclepro.2009.09.005

POTTING, J.; CURRAN, M.A.; BLOTTNITZ, H. From life cycle talking to taking action. International Journal of Life Cycle Assessment, v. 15, p. 326-329, 2010. http://dx.doi. org/10.1007/s11367-010-0167-4

REN, X. Cleaner production in China's pulp and paper industry. Journal of Cleaner Production, v. 6, p. 349-355, 1998.

RENWICK, D.; REDMAN, T.; MAGUIRE, S. Green HRM: a review, process model, and a research agenda. University of Sheffield Management School, 2008. p. 1-32. (Working Paper Series, Discussion Paper, n. 2008.1).

SAMMALISTO, K.; BRORSON, T.; Training and communication in the implementation of environmental mangagement systems (ISO 14001): a case study at the University of Gävle, Sweden. Journal of Cleaner Production, v. 16, n. 3, p. 299-309, 2008. http://dx.doi.org/10.1016/j. jclepro.2006.07.029

SARKIS, J.; GONZALEZ-TORRE, P.; ADENSO-DIAZ, B. Stakeholder pressure and the adoption of environmental practices: the mediating effect of training. Journal of Operations Management, v. 28, p. 163-176, 2010. http:// dx.doi.org/10.1016/j.jom.2009.10.001

STONE, L. J. When case studies are not enough: the influence of corporate culture and employee attitudes on the success of cleaner production initiatives. Journal of Cleaner Production, v. 8, n. 5, p. 353-359, 2000. http:// dx.doi.org/10.1016/S0959-6526(00)00037-8

UNNIKRISHNAN, S.; HEDGE, D. S.Environmental training and cleaner production in Indian industry - A micro-level study. Resources, Conservation and Recycling, v. 50, n. 4, p. 427-441, 2007. http://dx.doi.org/10.1016/j. resconrec.2006.07.003

VOSS, C. et al. Case resarch in operations management. International Journal of Operations \& Production Management, v. 22, n. 2, p. 195-219, 2002. http:// dx.doi.org/10.1108/01443570210414329 
WINN, M. 1.; ANGELL, L. C. Towards a process model of corporate greening. Organization Studies, v. 21, p. 1119-1147, 2000. http://dx.doi. org/10.1177/0170840600216005

WOOLVERTON, A.; DIMITRI, C. Green marketing: are environmental and social objectives compatible with profit maximization? Renewable Agriculture and Food Systems, v. 25, n. 2, p. 90-98, 2010. http://dx.doi. org/10.1017/S1742170510000128

YANG, C. et al. Mediated effect of environmental management on manufacturing competitiveness: an empirical study. International Journal of Production Economics, v. 123, p. 210-220, 2010. http://dx.doi.org/10.1016/j. ijpe.2009.08.017

YIN, R. Case Study Research: Design and Methods. Sage Publications: USA, 1989.

\section{Agradecimentos}

À Fapesp - Fundação de Amparo à Pesquisa do Estado de São Paulo - pelo financiamento desta pesquisa, por meio do processo Fapesp 2008/50807-0. Aos dois revisores anônimos da Revista Produção, que muito contribuíram para a melhoria deste artigo.

\title{
Environmental training in organizations with ISO 14001 certification: a multiple case study and identification of co-evolution with environmental management
}

\begin{abstract}
The objective of this research is to understand the characteristics of environmental training at some Brazilian companies. Nine case studies were carried out in firms certified by 1SO 14001. These companies are leaders in their market segments. Several interviews were conducted in each case. Documents were collected and visits for direct observation were made. Results present the classification of companies in evolutionary stages of environmental management, the most common topics of the training environment, the differentiation of environmental training topics according to the hierarchical levels and the best practices offered on environmental training. The main contribution of this research is the identification of the co-evolution between the stage of corporate environmental management and the level of environmental training.
\end{abstract}

Keywords

Environmental training. Environmental management. Green human resource management. Environmental sustainability. Brazil. 